\title{
Analysis of the Voltage Stability of Power System with Large Wind Power Integration
}

\author{
${ }^{1}$ Weldon K. Koskei, ${ }^{2}$ David K. Murage, ${ }^{3}$ Samuel Kangethe \\ ${ }^{1}$ MSc Student, Department of Electrical and Electronic Engineering, Jomo Kenyatta University of Agriculture and Technology, \\ Kenya \\ ${ }^{2,3}$ Professor, Department of Electrical and Electronic Engineering, Jomo Kenyatta University of Agriculture and Technology, \\ Kenya
}

Abstract - Renewable energy deployment is currently advocated globally as a key component in providing access to green energy, addressing current climate change and increasing energy services as well as creating economic opportunities. Wind power generation is one of renewable energy sources which are gaining more interest as a generation source to inject more power capacity to power system grid. This is as a result of the fluctuation of fuel prices affecting thermal power and unfavorable weather conditions affecting hydropower plants. According to world wind energy association, the total world wind power installed capacity had reached $651 \mathrm{GW}$ by end of 2019 and is estimated to reach $8 \%$ of world electricity market by 2035. Many governments in the world today have enacted policies to promote renewable energy rollout to meet the ever increasing electricity demand and reduce dependence of power from hydro and thermal plants.

Wind induction generators are non-conventional and use different technology and their output depend on changing weather conditions. This generates power quality challenges such as uncontrollable reactive power and voltage fluctuations which negatively affect power system voltage stability. Since the rate of connecting wind power plants into transmission power systems is increasing rapidly, there is need to investigate their impact on power system voltage stability. This in turn will help power system operators and planners in their daily power system operations. This paper aims at analyzing the impact of wind power integration on power system voltage stability. Line stability Index $\left(L_{m n}\right)$ and Fast Voltage Stability Index (FVSI) were used to analyze voltage profiles. These line voltage indices show the proximity of transmission lines to voltage instability state. IEEE 30 bus system was used as a test system to carry out this research study. The research also investigated the effects of different location and different penetration levels of wind power into the power system using MATLAB simulation software.

Keywords: Induction Generators, Reactive Power, Voltage Stability, Fast Voltage Stability Index, Line Stability Index.

\section{INTRODUCTION}

Wind energy is currently playing key role in establishing a friendly and environmentally sustainable economy which is low in carbon. It was initially used as a source of energy to drive ships, grind grains and pump water.

Wind energy was first used to generate electricity in the late 19th century and it gained more interest in around 1970s due to oil crisis and more awareness on conservation of resources [1]. Wind energy was later used in remote power systems, charging batteries, isolated or island power systems and in residential power systems. The current available wind turbines range from $100 \mathrm{~kW}$ to $5 \mathrm{MW}$. The wind power generation rapidly increased due to industrial and governmental initiatives.

The wind turbines development has grown rapidly which has led to continuous growth of global wind market. Most of the electricity industries globally are currently not able to meet power demand for domestic and industrial purposes. Therefore there is need for more electricity generation so that it can provide electricity to larger population as well as supporting economic growth. Electric power generated from hydropower is not reliable during dry seasons and thermal power plants uses oil products which is greatly affected by ever rising oil prices leading to negative impacts on economic activities. Most governments in the world have enacted policies to promote renewable energy deployment to meet the increasing electricity demand and reduce dependence of power from hydro and thermal plants. Wind power generation as one of the renewable energy is gaining more interest in adding more power generation capacity to power system grid [2], [3]. The nature of wind power generation poses integration stability challenges to the existing electric power systems.

The generator technology used in most wind turbines is induction generator technology which consumes reactive power from the grid. This wind generator technology together with variation in wind energy generation lead to uncontrollable reactive power, voltage distortion, voltage 
ISSN (online): 2581-3048

fluctuations as well as power fluctuations which affect power quality and stability of the power system.

The high level of industrialization globally has led to increase demand for electric power but the expansion of power system infrastructure is limited by financial constraints. This has led to operation of power system close to its operating stability limits. This overloaded operation condition of power system leads to instability challenges like voltage instability due to inability of the power system to supply required reactive power. Integration of induction wind generators which consume reactive power from already stressful power system might worsen the condition.

The impact of wind power integration on voltage stability of power system was investigated and results obtained from simulating standard IEEE 30 bus system were discussed.

\section{VOLTAGE STABILITY}

The demand for electric power is ever increasing in many power systems globally due to rapid growth in industrialization. This has led to operation of power systems closer to stability limits which make the system vulnerable to instability challenges like voltage instability. Many researchers have developed interest in studying voltage stability due to its cause for blackout incidents in many electric markets globally.

Voltage stability is referred to as ability of the power system to maintain steady voltages at all buses in the system under a normal operating conditions and after being subjected to a disturbance [4], [5]. Voltage instability is mainly caused by increase in the load demand and inability of the system to supply required reactive power which leads to uncontrollable voltage drops. Voltage stability is classified into large disturbance and small disturbance voltage stability. Large disturbance voltage stability is concerned with maintaining voltages after large disturbances such as faults and loss of generation in the system while small disturbance voltage stability deals with maintaining voltages after small disturbances such as gradual changes of the loads in the system.

There are tools used to approximate the voltage stability status of the power system. Voltage stability indices are examples of these tools used in power system to gauge the proximity of a particular operating point to voltage instability state. They shows how close a given operating point is to the steady state voltage stability margin. They are helpful to power system operators in their system operations since they show a real time state of the power system. They are also useful during power system designing and planning of operations. Fast voltage stability index developed by [6] and line stability index developed by [7] were used in this paper to show how close the system is to voltage collapse. The line stability index $\left(L_{m n}\right)$ is formulated as follows:

Where

$$
L_{m n}=\frac{4 \mathrm{X}_{\mathrm{ij}} \mathrm{Q}_{\mathrm{j}}}{\left.\left[\mathrm{V}_{\mathrm{i}} \operatorname{Sin}(\theta-\delta)\right]\right]^{2}}
$$

$$
\begin{aligned}
& X_{i j} \text { - line reactance } \\
& Q_{j} \text { - receiving end reactive power } \\
& V_{i} \text { - sending end voltage } \\
& \theta \text { - line impedance angle } \\
& \delta \text { - angle between sending end and receiving end } \\
& \text { voltage }
\end{aligned}
$$

The value of $\mathrm{L}_{\mathrm{mn}}$ is used to show how close the line is to voltage collapse. Lines with $\mathrm{L}_{\mathrm{mn}}$ values close to zero are considered stable but those lines with values close to 1 are considered unstable. This index is capable of identifying critical areas and most critical lines in a power system network. This Fast Voltage stability index $\left(F V S I_{i j}\right)$ is formulated as:

Where

$$
F V S I_{i j}=\frac{4 Z_{i j}^{2} Q_{j}}{V_{i}{ }^{2} \mathrm{X}_{\mathrm{ij}}}
$$

$Z_{i j}$ - line impedance

$Q_{j}$ - receiving end reactive power

$V_{i}$ - sending end voltage

$\mathrm{X}_{\mathrm{ij}}$ - line reactance

This index shows the proximity of a line to voltage collapse. The lines with FVSI value close to 0 are considered stable while those with values close to 1 are termed as unstable. Just like $\mathrm{L}_{\mathrm{mn}}$ index, FVSI index have capability of identifying critical lines and most critical areas in a power system network.

\section{TYPES OF WIND POWER GENERATORS}

Wind generator technology is one of the limiting factors in development of wind turbines. AC Asynchronous WTGs have been widely used in wind turbine applications and below are two main types:

\subsection{Fixed speed induction generators (FSIG) \\ 3.2 Doubly fed induction generators (DFIG)}

\subsection{Fixed Speed Induction Generators (FSIG)}

FSIGs have squirrel cage rotors and normally referred to as squirrel cage induction generators SCIGs [8]. Fig 1 shows schematic diagram of FSIG. 
ISSN (online): 2581-3048

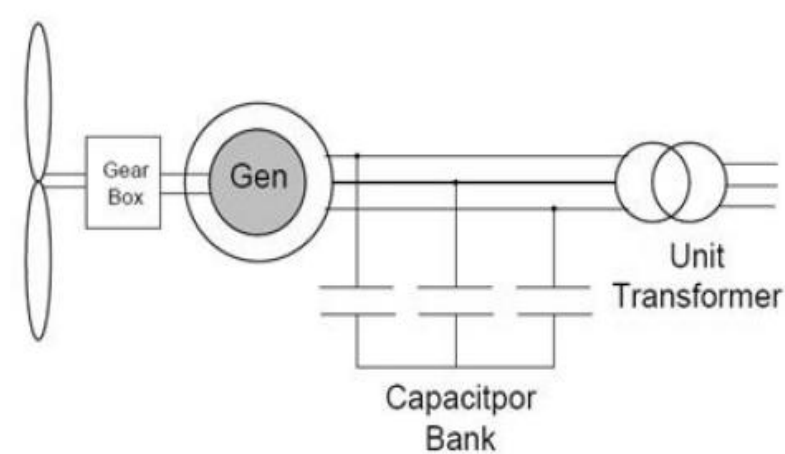

Figure 1: Schematic Representation of FSIG

The stator is connected to the power system grid through a transformer while the rotor is connected to the wind turbine system through a gearbox. The rotor is considered to run within a narrow range of speeds hence termed as fixed speed induction generators. FSIGs normally operate at $1500 \mathrm{rpm}$ for $50 \mathrm{~Hz}$ electric power system grid [9]-[10].

FSIGs do not have capability to control output voltage and hence reactive power is supplied from external sources. These WTGs are also large in size, noisy and have low efficiency.

\subsection{Doubly Fed Induction Generators (DFIG)}

DFIGs have wound rotors and are currently widely used in wind power generation [11]-[14]. The commercial wind turbine systems of DFIGs have increased to 5MW. Fig 2 shows schematic diagram of DFIG.

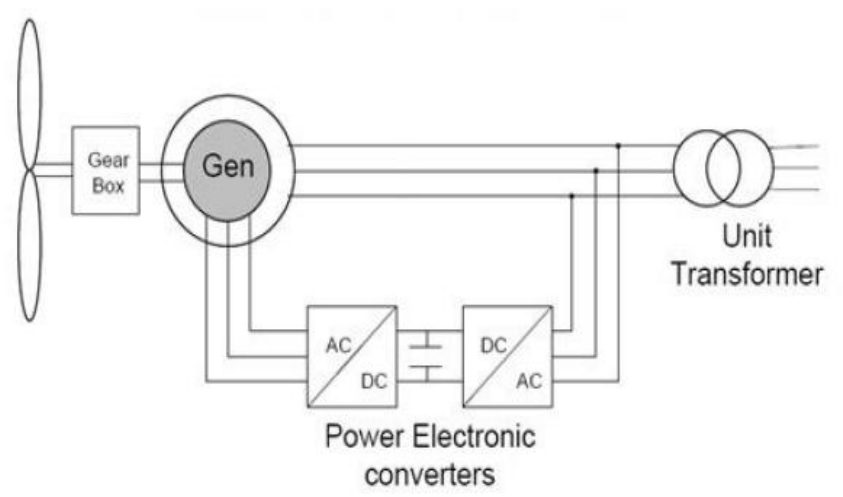

Figure 2: Schematic Representation of DFIG

The stator is connected to the power system network through transformers while the rotor is connected to the grid through PMW power converters. These power converters control rotor circuit current, frequency as well as phase angle shifts. They operate at wide range of speeds hence can produce high energy, reduced mechanical stress and power fluctuations as well as providing capability for reactive power control.
DFIGs have capability to operate in sub-synchronous and super-synchronous states. The stator transfers power to the power system grid only while the rotor can transfer power in both directions with the help of PMW power converters which can supply voltage and current at different phase angles. During sub-synchronous, rotor side converter (RSC) acts as an inverter while grid side converter (GSC) act as a rectifier and active power flows from the grid to the rotor. In supersynchronous state, RSC act as rectifier while GSC operates as an inverter and hence active power will flow from stator and rotor to the power system grid.

\section{TEST SYSTEM AND SIMULATIONS RESULTS}

The impact of wind power integration on power system voltage stability was investigated by performing load flow analysis on standard IEEE 30 bus system and its system data is as shown in the appendix. This test system is as shown in Fig 3. This system comprises of six generator buses, twenty four load buses and forty one interconnected transmission lines. Static loads were considered in this simulation.

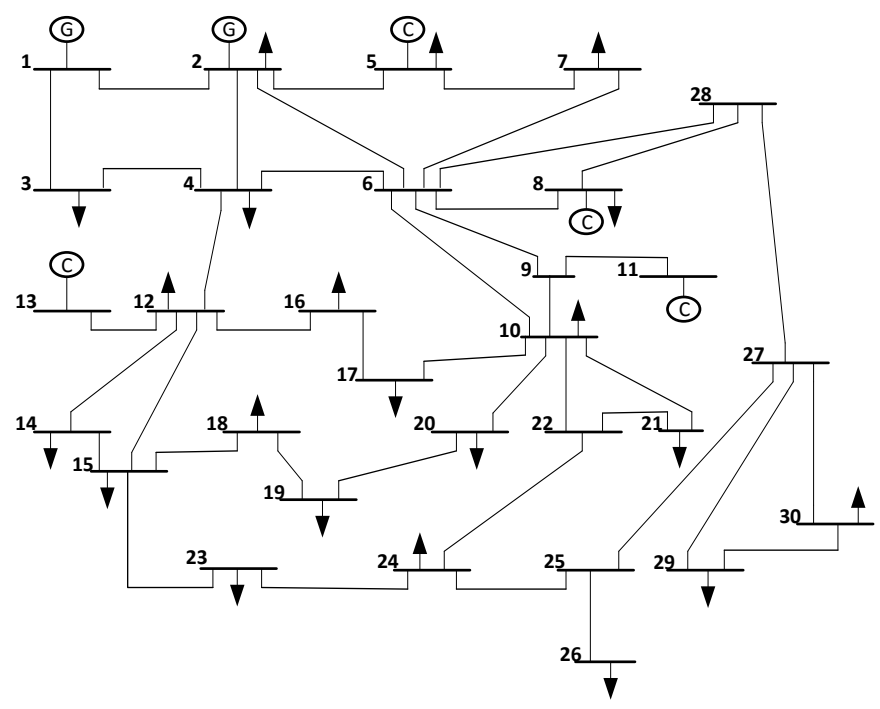

Figure 3: Standard IEEE 30 Bus Test System

Double fed induction generators were used to carry out this study. The simulations were carried out first without wind power integration and after wind power integration into test power system.

Different wind power integration locations were considered and in each location different penetration levels were analyzed from $10 \%$ to $30 \%$ of the total power generated. The results obtained in each case were used to calculate the voltage stability indices of some lines and these indices compared to quantify how the inclusion of wind power integration affects voltage profiles of the power system. Table I shows calculated indices on some lines when wind power was integrated at bus 5 and table II shows results obtained 
when point of integration is bus 15 while table III results obtained when bus 25 considered as the integration point. All simulations in this study were carried out at base loading.

Table 1: Wind power integration at bus 5

\begin{tabular}{|c|c|c|c|c|c|c|c|c|c|}
\hline \multirow{3}{*}{$\begin{array}{c}\text { Fro } \\
\mathrm{m} \\
\text { Bus }\end{array}$} & \multirow{2}{*}{$\begin{array}{l}\text { To } \\
\text { Bus }\end{array}$} & \multicolumn{2}{|c|}{$0 \%$} & \multicolumn{2}{|c|}{$10 \%$} & \multicolumn{2}{|c|}{$20 \%$} & \multicolumn{2}{|c|}{$30 \%$} \\
\hline & & FVSI & $\mathrm{L}_{\mathrm{mn}}$ & FVSI & $\mathrm{L}_{\mathrm{mn}}$ & FVSI & $\mathrm{L}_{\mathrm{mn}}$ & FVSI & $\mathrm{L}_{\mathrm{mn}}$ \\
\hline & & & & & & & & & \\
\hline 2 & 5 & 0.014 & 0.012 & 0.014 & 0.012 & 0.014 & 0.013 & 0.015 & 0.014 \\
\hline 5 & 7 & 0.020 & 0.018 & 0.020 & 0.018 & 0.021 & 0.020 & 0.025 & 0.022 \\
\hline 2 & 4 & 0.021 & 0.023 & 0.021 & 0.023 & 0.023 & 0.024 & 0.030 & 0.028 \\
\hline 2 & 6 & 0.024 & 0.022 & 0.024 & 0.022 & 0.025 & 0.024 & 0.039 & 0.037 \\
\hline 1 & 2 & 0.009 & 0.007 & 0.009 & 0.007 & 0.010 & 0.008 & 0.023 & 0.019 \\
\hline 6 & 7 & 0.025 & 0.023 & 0.025 & 0.023 & 0.027 & 0.025 & 0.049 & 0.043 \\
\hline 16 & 17 & 0.016 & 0.015 & 0.016 & 0.015 & 0.016 & 0.015 & 0.016 & 0.025 \\
\hline 27 & 29 & 0.253 & 0.257 & 0.253 & 0.257 & 0.253 & 0.257 & 0.253 & 0.257 \\
\hline
\end{tabular}

The values of the indices calculated for some branches in table I above were obtained by first carrying out simulations for base loading without wind power integration. The wind power was introduced into the system first at $10 \%$ of the total generated power and then $20 \%$ and finally $30 \%$. The voltage stability indices were calculated for each integration case and compared with those obtained without wind power integration into the system. Results in table I shows that there is little impact when wind power integrated at $10 \%$ but there is slight impact at $20 \%$ integration. There is also small decrease of voltage profiles at $30 \%$ wind power integration shown by higher values of indices as compared with other cases. Bus 5 which is a point of wind power integration in this case is considered as generation area since most generators are concentrated around this bus. Hence the reactive power drawn by induction wind turbines generators is easily compensated leading to small impact on voltage stability. It is also noted that there is no impact on the lines far away from the point of integration.

Table 2: Wind power integration at bus 15

\begin{tabular}{|c|c|c|c|c|c|c|c|c|c|}
\hline Fro & To & $0 \%$ & & $10 \%$ & & $20 \%$ & & $30 \%$ & \\
\hline $\begin{array}{l}\mathrm{m} \\
\text { Bus }\end{array}$ & Bus & FVSI & $\mathrm{L}_{\mathrm{mn}}$ & FVSI & $\mathrm{L}_{\mathrm{mn}}$ & FVSI & $\mathrm{L}_{\mathrm{mn}}$ & FVSI & $\mathrm{L}_{\mathrm{mn}}$ \\
\hline 14 & 15 & 0.012 & 0.011 & 0.053 & 0.053 & 0.143 & 0.129 & 0.278 & 0.262 \\
\hline 12 & 15 & 0.032 & 0.030 & 0.060 & 0.049 & 0.120 & 0.122 & 0.238 & 0.228 \\
\hline 15 & 18 & 0.021 & 0.020 & 0.062 & 0.058 & 0.136 & 0.135 & 0.263 & 0.263 \\
\hline 15 & 23 & 0.035 & 0.038 & 0.062 & 0.061 & 0.139 & 0.137 & 0.273 & 0.273 \\
\hline 12 & 14 & 0.029 & 0.027 & 0.030 & 0.029 & 0.060 & 0.043 & 0.101 & 0.082 \\
\hline 18 & 19 & 0.037 & 0.035 & 0.043 & 0.043 & 0.072 & 0.069 & 0.124 & 0.119 \\
\hline 2 & 5 & 0.014 & 0.013 & 0.014 & 0.013 & 0.014 & 0.012 & 0.014 & 0.012 \\
\hline 27 & 29 & 0.253 & 0.257 & 0.253 & 0.257 & 0.267 & 0.269 & 0.293 & 0.282 \\
\hline
\end{tabular}

The same procedure was repeated by first carrying out load flows simulations without wind power integration and then integrates it at bus 15 which is considered as transmission area. The branches around the point of integration were mostly analyzed to assess the impact of wind power inclusion. Just like the first case, there is small impact at $10 \%$ penetration level but higher effect at $30 \%$ as shown by higher indices values. There is higher decrease of voltage stability at this point of integration as compared with the first case as shown by higher values of the indices. This is because at this integration point there is less reactive power as compared with generation area in the first case.

Table 3: Wind power integration at bus 25

\begin{tabular}{cccccccccc}
\hline \multirow{2}{*}{$\begin{array}{c}\text { Fro } \\
\mathrm{m}\end{array}$} & To & \multicolumn{2}{c}{$0 \%$} & \multicolumn{2}{c}{$10 \%$} & \multicolumn{2}{c}{$20 \%$} & \multicolumn{2}{c}{$30 \%$} \\
\cline { 3 - 9 } Bus & & FVSI & $\mathrm{L}_{\mathrm{mn}}$ & FVSI & $\mathrm{L}_{\mathrm{mn}}$ & FVSI & $\mathrm{L}_{\mathrm{mn}}$ & FVSI & $\mathrm{L}_{\mathrm{mn}}$ \\
\hline 25 & 26 & 0.254 & 0.252 & 0.280 & 0.262 & 0.302 & 0.281 & 0.382 & 0.360 \\
24 & 25 & 0.047 & 0.048 & 0.241 & 0.241 & 0.290 & 0.288 & 0.311 & 0.302 \\
25 & 27 & 0.031 & 0.029 & 0.258 & 0.249 & 0.313 & 0.302 & 0.383 & 0.384 \\
22 & 24 & 0.023 & 0.022 & 0.140 & 0.139 & 0.148 & 0.141 & 0.211 & 0.207 \\
23 & 24 & 0.040 & 0.038 & 0.130 & 0.130 & 0.140 & 0.135 & 0.163 & 0.160 \\
27 & 29 & 0.253 & 0.257 & 0.266 & 0.261 & 0.280 & 0.272 & 0.341 & 0.344 \\
2 & 5 & 0.014 & 0.012 & 0.014 & 0.012 & 0.014 & 0.012 & 0.014 & 0.012 \\
16 & 17 & 0.016 & 0.025 & 0.029 & 0.028 & 0.030 & 0.029 & 0.034 & 0.033 \\
\hline
\end{tabular}

The results in table III were obtained by carrying out simulations at different wind power penetration at bus 25 which is considered as load area. Just like the other scenarios, the values of the indices generally increase with increase in penetration level.

There is higher decrease in voltage stability as indicated by higher indices when the point of wind power integration is electrically far away from generation area as shown in table III. The simulations without wind power integration shows that the values of indices at load area are higher than those at generation or transmission area. These indicate that buses at load area are weak as compared to those at generation and transmission area. Hence inclusion of induction wind power generators at load area further decrease voltage profiles and impact increases with the increase in penetration levels.

\section{CONCLUSION}

The effect of wind power integration on power system voltage stability was investigated in this study. The research shows that the effect varies with penetration level and integration point of the wind power plants. There is greater impact of power system voltage instability at load area as compared to generation area. The voltage instability state is higher with the increase in penetration level. Hence the reactive power compensation will depend on location of wind power integration to the system and also the level of penetration to the power system grid. 
ISSN (online): 2581-3048

\section{REFERENCES}

[1] Manwell, J. F., Mc Gowan, J. G., \& Rogers, A. L. (2009). Wind energy explained: theory, design and application. 2nd edition, Wiley, England.

[2] Shanker, T., \& Singh, R. K. (2012). Wind energy conversion system: A review. StudentsConference on Engineering and Systems (SCES), 1-6.

[3] World wind energy association, Quarterly Bulletin, Special Issue 2015.

[4] P. Kundur, Power System Stability and Control, McGraw-Hill, 1993

[5] C. W. Taylor, Power System Voltage Stability McGraw-Hill, 1994.

[6] T. K. A. R. Ismail Musirin, "Novel Fast Voltage Stability Index (FVSI) for Voltage Stability Analysis in Power Transmission System," in Student Conference on Research and Development Proceeding, 2002, pp. 265-268.

[7] M. Moghavvemi, "New method for indicating voltage stability in power system" Proceedings of IEEE International Conference on Power Engineering, Singapore, IPEC, 1997, pp. 223-227.

[8] Zhang, M., Wang, W., Chen, Y. R., \& Coombs, T. (2012). Design methodology of HTSbulk machine for direct-driven wind generation. IEEE Transactions on Applied Superconductivity,22(3), 5201804.
[9] Abo-Khalil, A. G. (2011). A new wind turbine simulator using a squirrel-cage motor for wind power generation systems. IEEE Ninth International Conference on Power Electronics and Drive Systems (PEDS), 750-755.

[10] A.Sokolovs, L. Grigans, E. Kamolins, J. Voitkans, “ An Induction Motor Based Wind Turbine Emulator," Latvian Journal of Physics and Technical Sciences, 51(2), 2014, 11-21.

[11] Polinder, H. (2011). Overview and trends in wind turbine generator systems",. IEEE Power and Energy Society General Meeting, 1-8.

[12] Delli, Colli. V., Marignetti, F., \& Attaianese, C. (2012). Analytical and multiphysics approach to the optimal design of a 10-MW DFIG for direct-drive wind turbines. IEEE Transactions on Industrial Electronics, 59(7), 2791-2799.

[13] Ruviaro, M., Runcos, F., Sadowski, N., \& Borges, I. M. (2012). Analysis and test results of a brushless doubly fed induction machine with rotary transformer. IEEE Transactions on Industrial Electronics, 59(6), 2670-2677.

[14] M. Tazil, V. Kumar, R. C. Bansal, S. Kong, Z. Y. Dong, W. Freitas, and H. D. Mathur, "Three-phase doubly fed induction generators: An overview," IET Elect. Power Appl., vol. 4, no. 2, pp. 75-89, Feb. 2010 .

\section{APPENDIX}

IEEE 30 BUS SYSTEM DATA

Table A1 : Bus Data

\begin{tabular}{|c|c|c|c|c|c|c|c|}
\hline $\begin{array}{c}\text { Bus } \\
\text { No }\end{array}$ & type & Pd & Qd & Vm & Va & Vmax & Vmin \\
\hline 1 & 3 & 0 & 0 & 1.06 & 0 & 1.06 & 0.94 \\
\hline 2 & 2 & 21.7 & 12.7 & 1.043 & -5.48 & 1.06 & 0.94 \\
\hline 3 & 1 & 2.4 & 1.2 & 1.021 & -7.96 & 1.06 & 0.94 \\
\hline 4 & 1 & 7.6 & 1.6 & 1.012 & -9.62 & 1.06 & 0.94 \\
\hline 5 & 2 & 94.2 & 19 & 1.01 & -14.37 & 1.06 & 0.94 \\
\hline 6 & 1 & 0 & 0 & 1.01 & -11.34 & 1.06 & 0.94 \\
\hline 7 & 1 & 22.8 & 10.9 & 1.002 & -13.12 & 1.06 & 0.94 \\
\hline 8 & 2 & 30 & 30 & 1.01 & -12.1 & 1.06 & 0.94 \\
\hline 9 & 1 & 0 & 0 & 1.051 & -14.38 & 1.06 & 0.94 \\
\hline 10 & 1 & 5.8 & 2 & 1.045 & -15.97 & 1.06 & 0.94 \\
\hline 11 & 2 & 0 & 0 & 1.082 & -14.39 & 1.06 & 0.94 \\
\hline 12 & 1 & 11.2 & 7.5 & 1.057 & -15.24 & 1.06 & 0.94 \\
\hline 13 & 2 & 0 & 0 & 1.071 & -15.24 & 1.06 & 0.94 \\
\hline 14 & 1 & 6.2 & 1.6 & 1.042 & -16.13 & 1.06 & 0.94 \\
\hline 15 & 1 & 8.2 & 2.5 & 1.038 & -16.22 & 1.06 & 0.94 \\
\hline 16 & 1 & 3.5 & 1.8 & 1.045 & -15.83 & 1.06 & 0.94 \\
\hline 17 & 1 & 9 & 5.8 & 1.04 & -16.14 & 1.06 & 0.94 \\
\hline 18 & 1 & 3.2 & 0.9 & 1.028 & -16.82 & 1.06 & 0.94 \\
\hline
\end{tabular}




\begin{tabular}{|l|c|c|c|c|c|c|c|}
\hline 19 & 1 & 9.5 & 3.4 & 1.026 & -17 & 1.06 & 0.94 \\
\hline 20 & 1 & 2.2 & 0.7 & 1.03 & -16.8 & 1.06 & 0.94 \\
\hline 21 & 1 & 17.5 & 11.2 & 1.033 & -16.42 & 1.06 & 0.94 \\
\hline 22 & 1 & 0 & 0 & 1.033 & -16.41 & 1.06 & 0.94 \\
\hline 23 & 1 & 3.2 & 1.6 & 1.027 & -16.61 & 1.06 & 0.94 \\
\hline 24 & 1 & 8.7 & 6.7 & 1.021 & -16.78 & 1.06 & 0.94 \\
\hline 25 & 1 & 0 & 0 & 1.017 & -16.35 & 1.06 & 0.94 \\
\hline 26 & 1 & 3.5 & 2.3 & 1 & -16.77 & 1.06 & 0.94 \\
\hline 27 & 1 & 0 & 0 & 1.023 & -15.82 & 1.06 & 0.94 \\
\hline 28 & 1 & 0 & 0 & 1.007 & -11.97 & 1.06 & 0.94 \\
\hline 29 & 1 & 2.4 & 0.9 & 1.003 & -17.06 & 1.06 & 0.94 \\
\hline 30 & 1 & 10.6 & 1.9 & 0.992 & -17.94 & 1.06 & 0.94 \\
\hline
\end{tabular}

Table A2: Generator Data

\begin{tabular}{|c|c|c|c|c|c|c|c|c|}
\hline $\begin{array}{c}\text { Bus } \\
\text { No }\end{array}$ & Pg & Qg & $\begin{array}{c}\text { Qm } \\
\mathrm{ax}\end{array}$ & $\begin{array}{c}\text { Qm } \\
\text { in }\end{array}$ & Vg & $\begin{array}{c}\mathrm{mB} \\
\text { ase }\end{array}$ & $\begin{array}{c}\text { Pma } \\
\mathrm{x}\end{array}$ & $\begin{array}{c}\text { Pmi } \\
\mathrm{n}\end{array}$ \\
\hline 1 & 260.2 & -16.1 & 10 & 0 & 1.06 & 100 & 360.2 & 0 \\
\hline 2 & 40 & 50 & 50 & -40 & 1.045 & 100 & 140 & 0 \\
\hline 5 & 0 & 37 & 40 & -40 & 1.01 & 100 & 100 & 0 \\
\hline 8 & 0 & 37.3 & 40 & -10 & 1.01 & 100 & 100 & 0 \\
\hline 11 & 0 & 16.2 & 24 & -6 & 1.082 & 100 & 100 & 0 \\
\hline 13 & 0 & 10.6 & 24 & -6 & 1.071 & 100 & 100 & 0 \\
\hline
\end{tabular}

Table A3: Line Data

\begin{tabular}{|c|c|c|c|c|c|c|}
\hline $\begin{array}{c}\text { Line } \\
\text { No }\end{array}$ & $\begin{array}{c}\text { From } \\
\text { bus }\end{array}$ & $\begin{array}{c}\text { To } \\
\text { bus }\end{array}$ & $\mathrm{r}$ & $\mathrm{x}$ & $\mathrm{b}$ & ratio \\
\hline 1 & 1 & 2 & 0.0192 & 0.0575 & 0.0528 & 0 \\
\hline 2 & 1 & 3 & 0.0452 & 0.1652 & 0.0408 & 0 \\
\hline 3 & 2 & 4 & 0.057 & 0.1737 & 0.0368 & 0 \\
\hline 4 & 3 & 4 & 0.0132 & 0.0379 & 0.0084 & 0 \\
\hline 5 & 2 & 5 & 0.0472 & 0.1983 & 0.0418 & 0 \\
\hline 6 & 2 & 6 & 0.0581 & 0.1763 & 0.0374 & 0 \\
\hline 7 & 4 & 6 & 0.0119 & 0.0414 & 0.009 & 0 \\
\hline 8 & 5 & 7 & 0.046 & 0.116 & 0.0204 & 0 \\
\hline 9 & 6 & 7 & 0.0267 & 0.082 & 0.017 & 0 \\
\hline 10 & 6 & 8 & 0.012 & 0.042 & 0.009 & 0 \\
\hline 11 & 6 & 9 & 0 & 0.208 & 0 & 0.978 \\
\hline 12 & 6 & 10 & 0 & 0.556 & 0 & 0.969 \\
\hline 13 & 9 & 11 & 0 & 0.208 & 0 & 0 \\
\hline 14 & 9 & 10 & 0 & 0.11 & 0 & 0 \\
\hline 15 & 4 & 12 & 0 & 0.256 & 0 & 0.932 \\
\hline 16 & 12 & 13 & 0 & 0.14 & 0 & 0 \\
\hline 17 & 12 & 14 & 0.1231 & 0.2559 & 0 & 0 \\
\hline 18 & 12 & 15 & 0.0662 & 0.1304 & 0 & 0 \\
\hline 19 & 12 & 16 & 0.0945 & 0.1987 & 0 & 0 \\
\hline 20 & 14 & 15 & 0.221 & 0.1997 & 0 & 0 \\
\hline 21 & 16 & 17 & 0.0524 & 0.1923 & 0 & 0 \\
\hline 22 & 15 & 18 & 0.1073 & 0.2185 & 0 & 0 \\
\hline 23 & 18 & 19 & 0.0639 & 0.1292 & 0 & 0 \\
\hline 24 & 19 & 20 & 0.034 & 0.068 & 0 & 0 \\
\hline 25 & 10 & 20 & 0.0936 & 0.209 & 0 & 0 \\
\hline 26 & 10 & 17 & 0.0324 & 0.0845 & 0 & 0 \\
\hline & & & & & & \\
\hline 19 & & 0 \\
\hline
\end{tabular}


ISSN (online): 2581-3048

\begin{tabular}{|c|c|c|c|c|c|c|}
\hline 27 & 10 & 21 & 0.0348 & 0.0749 & 0 & 0 \\
\hline 28 & 10 & 22 & 0.0727 & 0.1499 & 0 & 0 \\
\hline 29 & 21 & 22 & 0.0116 & 0.0236 & 0 & 0 \\
\hline 30 & 15 & 23 & 0.1 & 0.202 & 0 & 0 \\
\hline 31 & 22 & 24 & 0.115 & 0.179 & 0 & 0 \\
\hline 32 & 23 & 24 & 0.132 & 0.27 & 0 & 0 \\
\hline 33 & 24 & 25 & 0.1885 & 0.3292 & 0 & 0 \\
\hline 34 & 25 & 26 & 0.2544 & 0.38 & 0 & 0 \\
\hline 35 & 25 & 27 & 0.1093 & 0.2087 & 0 & 0 \\
\hline 36 & 28 & 27 & 0 & 0.396 & 0 & 0.968 \\
\hline 37 & 27 & 29 & 0.2198 & 0.4153 & 0 & 0 \\
\hline 38 & 27 & 30 & 0.3202 & 0.6027 & 0 & 0 \\
\hline 39 & 29 & 30 & 0.2399 & 0.4533 & 0 & 0 \\
\hline 40 & 8 & 28 & 0.0636 & 0.2 & 0.0428 & 0 \\
\hline 41 & 6 & 28 & 0.0169 & 0.0599 & 0.013 & 0 \\
\hline
\end{tabular}

\section{Citation of this Article:}

Weldon K. Koskei, David K. Murage, Samuel Kangethe, "Analysis of the Voltage Stability of Power System with Large Wind Power Integration" Published in International Research Journal of Innovations in Engineering and Technology IRJIET, Volume 5, Issue 5, pp 52-58, May 2021. Article DOI https://doi.org/10.47001/IRJIET/2021.505009 